\title{
Oesophageal hiatal hernia: a radiological follow-up
}

\author{
SV. BORGESKOV, O. TRUE PEDERSEN, AND \\ THORKILD FREDERIKSEN
}

\author{
From the Department of Surgery $R$, Rigshospitalet, Copenhagen, Denmark
}

Hiatal hernia is a sub-group of diaphragmatic hernia, and is usually in the form of a sliding hernia. Part of the gastric fundus and the cardia itself are in an intrathoracic position, and the angle of the cardia is straightened out. Thus there is a possibility of regurgitation of acid gastric contents into the oesophagus. This gives rise to the typical symptoms of gaseous eructations, pyrosis, and oppression, and a tendency to a reflux of gastric contents when the patient is lying down or stooping. Oesophageal ulcerations and strictures may appear later, in direct consequence of the oesophagitis. In para-oesophageal hernia the cardia is in its proper place below the diaphragm and is sufficient, but part of the fundal area slides upwards along the oesophagus and remains within the thoracic cavity (Engberg, Thomsen, and Vesterdal, 1957). In that event, the symptoms are not due to regurgitation but to attacks of incarceration, and in large herniae to direct compression of intrathoracic viscera. However, a sliding hernia is frequently combined with a paraoesophageal hernia (Barrett, 1952), and since the condition is moreover often combined with other diseases of the stomach and biliary tract the symptoms may be extremely complex.

It was not until Morrison (1925) had demonstrated hiatal hernia by radiography of the ossophagus and stomach after the oral administration of contrast medium and Åkerlund (1926) had developed the radiological technique further that it was realized that hiatal hernia is a relatively common condition that by no means always gives rise to symptoms.

However, radiographic demonstration of hiatal hernia depends upon the technique, and more recent investigations have shown a varied frequency. Turner (1943) found hiatal hernia in 3.5\% of 1,500 patients having gastro-intestinal symptoms. Fick (1949) found the condition to be second in order of frequency among patients with dyspeptic complaints, occurring in $8.93 \%$ (as compared with duodenal ulcer in $17.8 \%$ ). Studying 300 symptom-free men over 50 years of age, Brick and Amory (1950) found $1.3 \%$ to have hiatal hernia. Pickard (1952) found hiatal hernia in $11 \%$ of all patients submitted to investigation of the oesophagus and stomach by contrast medium within one year. Lastly, Bloom (1947) found hiatal hernia in $16 \%$ of 100 consecutive studies of the stomach. In the series reviewed above, no distinction is made between sliding hernia and paraoesophageal hernia.

Shortly after the radiological diagnosis had become a reality, many clinics started treating their patients surgically, because surgery is the only remedial treatment and because the associated oesophagitis was only slightly influenced by medical management.

Conservative therapy is used only for patients in whom operation is contra-indicated or who have only mild complaints.

Key (1926) reported on the transpleural as well as the abdominal approach, but until the great upswing of thoracic surgery in the forties the abdominal method was in most common use.

In 1951 Allison described a new operation consisting mainly of the reconstruction of the angle between the stomach and the oesophagus, narrowing of the hiatus posteriorly, and suturing of the gastric fundus to the under-surface of the diaphragm. The approach was through a left-sided thoracotomy, and the incision into the diaphragm was parahiatal.

When he described the method, Allison also reported his first results. He did not mention the length of the follow-up period, but it must have been short. Out of 48 patients he operated upon, 45 had no recurrence and two had true recurrences. Similar favourable results have been reported by Hill, Chapman, and Morgan (1961), who submitted a series of 125 patients with only two recurrences and a follow-up of six years.

Crawford and DeBakey (1958) used the Allison method, but by the abdominal approach. They had $3.5 \%$ recurrences in 144 cases.

Sparks (1958) had 389 cases with 73 recurrences and, in addition, five cases with hernia through 
the diaphragmatic incision. Thirteen of the recurrences appeared more than three years after the operation.

The recurrence rate has been reported as 3 to $4 \%$ by Sweet (1953) and as $48 \%$ by Brintnall, Blome, and Tidrick (1961). In a series of 34 operated children, Thomsen (1955) found 15 recurrences.

In a follow-up of 45 patients with sliding hernia Werner and Wiklund (1959) found four radiological recurrences in patients operated upon by a modified Allison procedure. In addition, 14 patients without radiological recurrence had the same symptoms as before the operation.

Husfeldt, Andreassen, Lindenberg, and Thomsen (1960) reported 11 radiological recurrences among 29 patients who had been treated by a modified Allison method. Only three of these patients suffered from symptoms.

The object of the present paper is to submit the results of a follow-up on a series treated by the Allison operation, which has now been in use in this department for 12 years. From this it should be possible to assess its long-term value.

\section{PRESENT SERIES}

During the 10 -year period $1951-60$ a total of 99 patients were admitted to the Department of Surgery R, Rigshospitalet, Copenhagen, with suspected oesophageal hiatal hernia. Out of these patients, 29 did not have an Allison operation, but a few were treated primarily by gastro-oesophageal resection because of severe haemorrhage, ulcer, and stricture (Table I). Out of the remaining

T A B LE I PATIENTS WITH HIATAL HERNIA NOT SUBMITTED TO
OPERATION

\begin{tabular}{|c|c|c|c|c|}
\hline \multicolumn{4}{|c|}{$\begin{array}{l}\text { Reason why Allison Operation was not } \\
\text { Performed }\end{array}$} & \multirow{2}{*}{$\begin{array}{c}\begin{array}{c}\text { No. of } \\
\text { Patients }\end{array} \\
8 \\
6 \\
6 \\
4 \\
5\end{array}$} \\
\hline $\begin{array}{l}\text { No symptoms } \\
\text { Oesophageal stricture, } \\
\text { Conditions contra-indi } \\
\text { Advanced age } \\
\text { Refused operation }\end{array}$ & $\begin{array}{l}\text { severe } \\
\text { cating } \\
\cdots \\
\cdots\end{array}$ & $\begin{array}{l}\text { haemorrhage } \\
\text { haperation } \\
\text { o } \quad \ldots \\
\ldots \\
\ldots\end{array}$ & $\begin{array}{l}\cdots \\
\cdots \\
\cdots \\
\cdots\end{array}$ & \\
\hline Total & .. & . & . & 29 \\
\hline
\end{tabular}

patients, who underwent an Allison operation, 26 were men and 44 women, and their age distribution is shown in Figure 1.

The youngest patient was 22 and the oldest 83 years of age. About three-quarters were between 50 and 70 years.

The distribution of the various types of hernia is listed in Table II on the basis of the operative findings.
TABLE II

TYPE OF OESOPHAGEAL HIATAL HERNIA ACCORDING TO THE OPERATIVE FINDINGS

\begin{tabular}{|c|c|c|c|c|}
\hline Type of Hernia & & Males & Females & Total \\
\hline $\begin{array}{l}\text { Sliding hernia } \\
\text { Para-oesophageal hernia } \\
\text { 'Combined' herniae }\end{array}$ & $\begin{array}{l}\cdots \\
\cdots \\
\cdots\end{array}$ & $\begin{array}{r}17 \\
5 \\
4\end{array}$ & $\begin{array}{r}32 \\
6 \\
6\end{array}$ & $\begin{array}{l}49 \\
11 \\
10\end{array}$ \\
\hline
\end{tabular}

TAB LE III

DURATION OF SYMPTOMS AT THE TIME OF OPERATION

\begin{tabular}{|c|c|c|c|c|c|}
\hline \multicolumn{3}{|c|}{ Duration of Symptoms (yr) } & \multirow{2}{*}{$\begin{array}{c}\text { Males } \\
7 \\
3 \\
16\end{array}$} & \multirow{2}{*}{$\begin{array}{c}\text { Females } \\
\begin{array}{r}9 \\
14 \\
21\end{array}\end{array}$} & \multirow{2}{*}{$\begin{array}{c}\text { Total } \\
16 \\
17 \\
37\end{array}$} \\
\hline $\begin{array}{l}\text { Less than } 1 \\
1-3 \\
\text { More than } 3\end{array}$ & $\begin{array}{l}\cdots \\
\cdots \\
\cdots\end{array}$ & $\begin{array}{l}\ldots \\
\ldots \\
\ldots\end{array}$ & & & \\
\hline
\end{tabular}

TABLE IV

SYMPTOMS AND SIGNS IN RELATION TO TYPE OF HERNIA

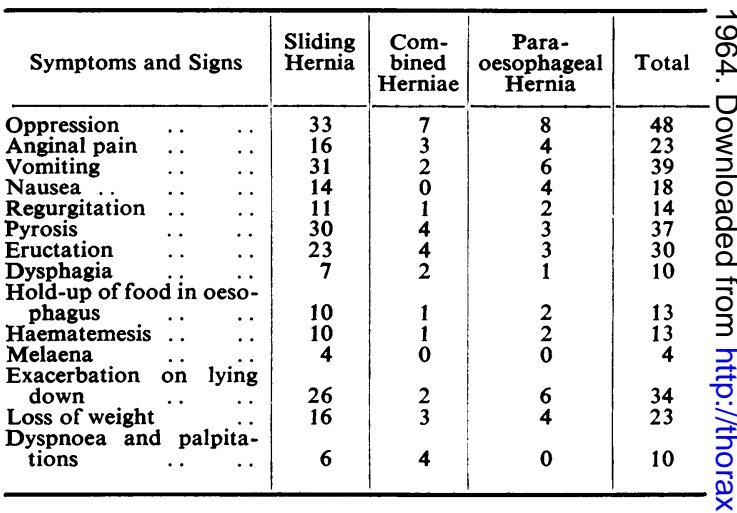

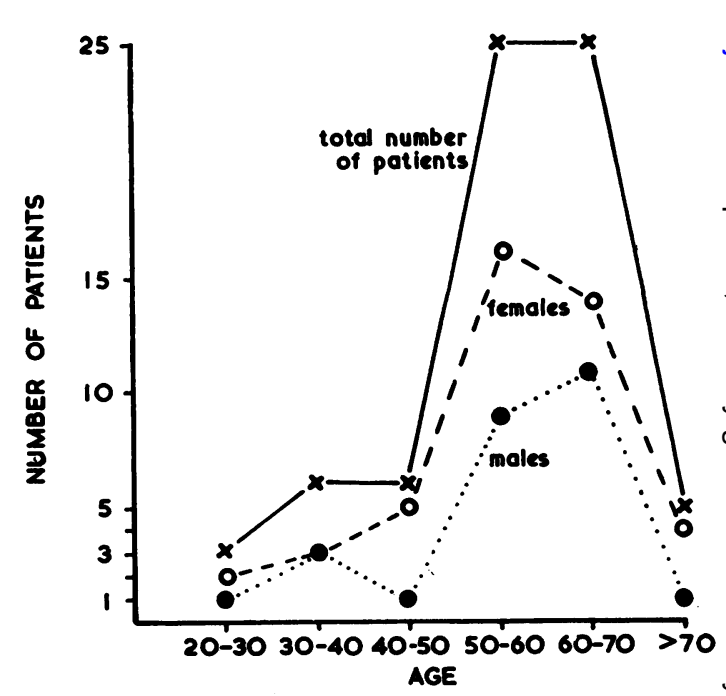

FIG. 1. Age distribution and sex ratio of 70 patients who underwent operation for oesophageal hiatal hernia. 
Table III gives the duration of symptoms. At the time of operation, about half the patients had been having symptoms for more than three years. The nature of the symptoms is shown in Table IV. The most common symptom, especially in patients with para-oesophageal hernia, was pain, partly in the form of retrosternal oppression and partly in the form of anginal pain radiating to the back. In cases of sliding hernia, pyrosis and eructations predominated, but even in this group many patients had a feeling of oppression.

Bleeding, in the form of haematemesis or melaena, occurred in one-quarter of the patients. In one it was so profuse that gastro-oesophageal resection was essential.

Table $\mathrm{V}$ lists the pre-operative radiographic findings compared with the operative findings. Ali the patients had pre-operative radiography of the oesophagus and stomach with a view to demonstrating hiatal hernia, but the original films for one patient could not be found. In 67 the preoperative diagnosis was hiatal hernia, while three patients were operated upon because of a suspicion of diaphragmatic relaxation, cardiospasm, and Morgagni hernia, respectively.

TABLE V

PRE-OPERATIVE RADIOGRAPHIC FINDINGS CORRELATED WITH OPERATIVE FINDINGS

\begin{tabular}{|c|c|c|c|c|}
\hline \multirow[b]{2}{*}{ Radiographic Findings } & \multirow[b]{2}{*}{ Total } & \multicolumn{3}{|c|}{ Operative Findings } \\
\hline & & $\begin{array}{l}\text { Slid- } \\
\text { ing } \\
\text { Hernia }\end{array}$ & $\mid \begin{array}{c}\text { Com- } \\
\text { bined } \\
\text { Herniae }\end{array}$ & $\begin{array}{l}\text { Para- } \\
\text { oesophageal } \\
\text { Hernia }\end{array}$ \\
\hline $\begin{array}{l}\text { Sliding hernia } \\
\text { Para-oesophageai hernia } \\
\text { Combined herniae } \\
\text { Hiatal hernia, not speci- }\end{array}$ & $\begin{array}{r}30 \\
18 \\
2\end{array}$ & $\begin{array}{r}28 \\
6 \\
1\end{array}$ & $\begin{array}{l}2 \\
6 \\
1\end{array}$ & $\begin{array}{l}\mathbf{0} \\
\mathbf{6} \\
\mathbf{0}\end{array}$ \\
\hline $\begin{array}{l}\text { fied } \begin{array}{ll}\text { Short oesophagus } & . \\
\text { Stricture } & \ldots\end{array} \\
\text { Grastric }\end{array}$ & $\begin{array}{r}12 \\
1 \\
4\end{array}$ & $\begin{array}{l}6 \\
1 \\
2\end{array}$ & $\begin{array}{l}2 \\
0 \\
0\end{array}$ & $\begin{array}{l}4 \\
0 \\
2\end{array}$ \\
\hline \begin{tabular}{llr} 
Gastric and & \multicolumn{2}{l}{ duodenal } \\
ulcer &. &. \\
Regurgitation &. &. \\
Cardiospasm &. &. \\
Morgagni hernia &. \\
Diaphragmatic relaxation
\end{tabular} & $\begin{array}{r}5 \\
14 \\
1 \\
1 \\
1\end{array}$ & $\begin{array}{r}5 \\
14 \\
1 \\
1 \\
1\end{array}$ & $\begin{array}{l}\mathbf{0} \\
\mathbf{0}\end{array}$ & $\begin{array}{l}\mathbf{0} \\
\mathbf{0}\end{array}$ \\
\hline
\end{tabular}

Oesophagoscopy was carried out in 24 patients, in 11 of whom a hernia was demonstrated. In 12 oesophagitis was found, in two stricture, and in one an oesophageal ulcer. In seven patients oesophagoscopy failed to show any abnormality.

Four of the patients had previously been treated by other surgical methods and had a re-operation, by the Allison procedure, because of a recurrence of the hernia, one, two, three, and eight years respectively after the primary operation.

The surgical method was in all cases left-sided thoracotomy, parahiatal incision of the diaphragm, reduction of the hernia, reconstruction of the cardial angle, suturing of the gastric fundus to the under-surface of the diaphragm, and narrowing of the hiatus by a few sutures applied to the crura posterior to the oesophagus, so that the hiatus only admitted a finger.

The post-operative complications were pulmonary in four patients and phlebitis of the lower extremities in three. One patient with embolus in the pulmonary artery and one with haemothorax died. This is a primary mortality of $2.8 \%$.

\section{FOLLOW-UP}

At the time of follow-up (Table VI) 14 of the 70 operated patients had died, two post-operatively and the others from intercurrent diseases.

T A B L E V I

STATUS AT FOLLOW-UP IN RELATION TO OPERATIVE FINDINGS

\begin{tabular}{l|c|c|c|c}
\hline & \multicolumn{2}{|c|}{ Operative Findings } & \\
\cline { 2 - 6 } & $\begin{array}{c}\text { Slid- } \\
\text { ing } \\
\text { Hernia }\end{array}$ & $\begin{array}{c}\text { Com- } \\
\text { bined } \\
\text { Herniae }\end{array}$ & $\begin{array}{c}\text { Para- } \\
\text { oesophageal } \\
\text { Hernia }\end{array}$ & Total \\
\hline $\begin{array}{l}\text { No. of patients followed } \\
\text { up . }\end{array}$ & 41 & 6 & 8 & 55 \\
$\begin{array}{l}\text { Symptom-free } \text { or im- } \\
\text { proved }\end{array}$ & 23 & 4 & 4 & 31 \\
$\begin{array}{l}\text { Patients with symptoms } \\
\text { Died during follow-up } \\
\text { period }\end{array}$ & 18 & 2 & 4 & 24 \\
\hline
\end{tabular}

During the follow-up period six patients had undergone various operations on the stomach and oesophagus, four because of recurrent hernia and two because of oesophageal stricture.

Out of the surviving patients, 55 attended the follow-up examination. One patient, living in Greenland, could not be traced.

Figure 2 gives the follow-up period, which ranged from two and a half to 12 years, average 7.6 years. It will be seen also that 49 of the patients had a follow-up period exceeding five years.

At follow-up 52 of the patients had radiography (Table VII) of the oesophagus and stomach after the oral administration of contrast medium. The investigations were done during screening, the exposures being made with the patients in the Trendelenburg position, lying on their right and left sides, supine, and prone (Thomsen, 1955).

In 31 cases the result was satisfactory as judged by the radiographic appearances. Eighteen patients had a recurrence of the hiatal hernia, but in most cases it was considerably smaller than before the operation. All the recurrences were of the sliding type except one, a para-oesophageal hernia that also recurred as such. In three of these patients radiography showed no true hernia, but there was 


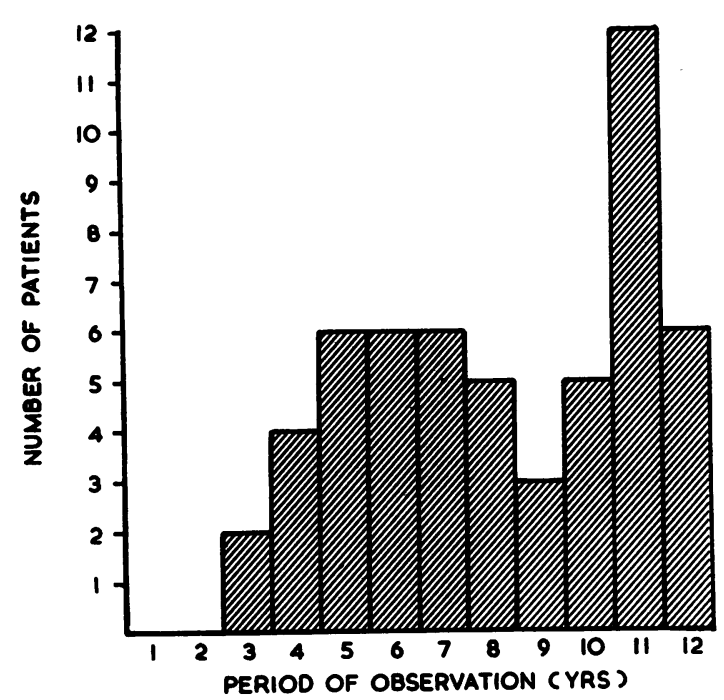

FIG. 2. Follow-up period for 55 patients.

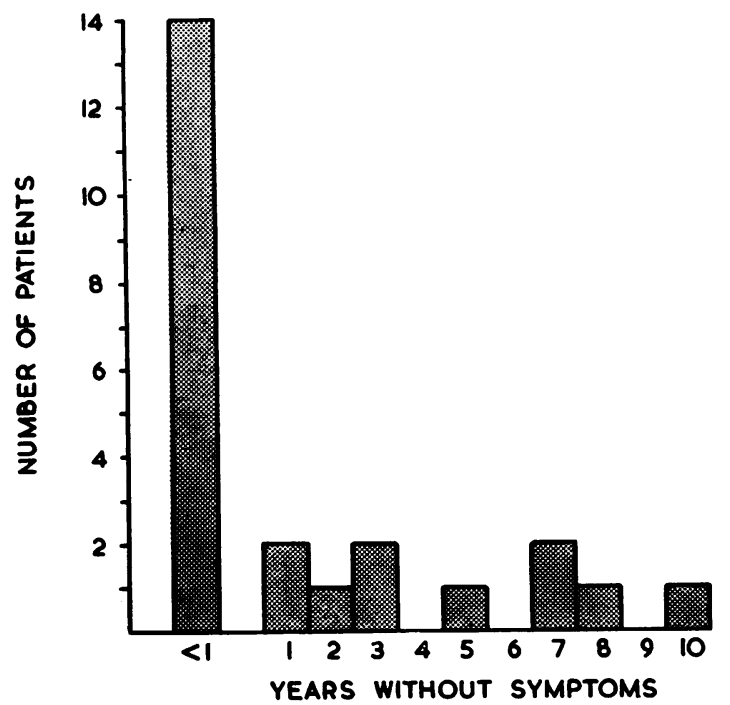

FIG. 3. Symptom-free interval for 24 patients having symptomatic recurrence.

regurgitation of gastric contents to the oesophagus through a wide cardia. One of the patients had an ulcer crater in the recurrent hernia.

In 31 patients the operation had been subjectively successful ; 15 were in perfect health and 16 had mild dyspeptic complaints, but they were less severe than before the operation.

Twenty-four patients complained of dyspeptic symptoms at follow-up. Out of this group 13 had been completely symptom-free during periods of
T A B L E V I I

RELATION BETWEEN SUBJECTIVE SYMPTOMS AND RADIOGRAPHIC FINDINGS AT FOLLOW-UP

\begin{tabular}{|c|c|c|c|c|}
\hline & $\begin{array}{c}\text { Slid- } \\
\text { ing } \\
\text { Hernia }\end{array}$ & $\begin{array}{l}\text { Com- } \\
\text { bined } \\
\text { Herniae }\end{array}$ & $\begin{array}{c}\text { Para- } \\
\text { oesophageal } \\
\text { Hernia }\end{array}$ & Total \\
\hline $\begin{array}{l}\text { Symptom-free or } \\
\text { improved: } \\
\text { No } X \text {-ray recurrence } \\
X \text {-ray recurrence } \quad .\end{array}$ & $\begin{array}{r}14 \\
5\end{array}$ & $\begin{array}{l}3 \\
1\end{array}$ & $\begin{array}{l}4 \\
1\end{array}$ & $\begin{array}{r}21 \\
7\end{array}$ \\
\hline $\begin{array}{l}\text { With symptoms: } \\
\text { No } X \text {-ray recurrence } \\
X \text {-ray recurrence } \quad .\end{array}$ & $\begin{array}{l}8 \\
7\end{array}$ & 1 & $\begin{array}{l}1 \\
3\end{array}$ & $\begin{array}{l}10 \\
11\end{array}$ \\
\hline $\begin{array}{l}\text { Gastro-oesophageal } \\
\text { resection }\end{array}$ & 2 & 0 & 1 & 3 \\
\hline
\end{tabular}

Three patients were not $X$-rayed at follow-up: one had undergone $c$ gastrectomy, one had heart disease, and one failed to attend.

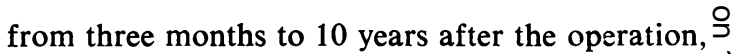
while 11 had had symptoms immediately after the $\overrightarrow{\vec{c}}$ operation. Four of the patients developed recur- $\frac{}{<}$ rent symptoms more than seven years after the herniotomy, and six from one to five years after (Fig. 3).

The correlation between signs and symptoms may be seen in Table VII.

Seven patients who reported improvement after the operation were found to have a radiographic

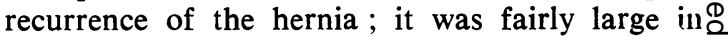

FIG. 4. A radiograph of the stomach, after administration of contrast medium, of a patient who reported subjective improvement after the operation shows a large recurrence. 
one (Fig. 4). On the other hand, 10 patients who were radiologically cured had the same symptoms as before the operation.

Information regarding the period from operation until death was obtainable for four patients who died in hospital one, four, four, and 10 years, respectively, after the operation. None of these patients had suffered from dyspeptic symptoms, and necropsy had shown no recurrence.

\section{DISCUSSION}

After radiography had made possible the diagnosis of hiatal hernia and thus had paved the way for surgery, there was a tendency to ascribe all dyspeptic symptoms in patients with radiological evidence of hiatal hernia to the presence of this abnormality.

In recent years increasing attention has been paid to the presence of complicating diseases (Crawford and DeBakey, 1958) giving rise to symptoms like those of hiatal hernia. It is worth bearing in mind another factor, which also appears from the present study (Table VII), that in the presence of hiatal hernia there is a poor correlation between symptoms and radiographic findings.

In analysing the results of a particular operation for hiatal hernia, it is important to evaluate the results as far as possible on the basis of objective criteria and not merely on the basis of the patient's symptoms. Improvement of symptoms because a complicating disease has got better cannot be counted to the credit of the operative method if objective signs of recurrence exist. If patients without subjective symptoms are not examined by radiography, the percentage of good results will be too high. Thus radiography must be considered the only applicable criterion by which the operative method can be assessed, since a persistence of symptoms in the absence of radiological recurrence cannot be blamed on the operative method. Often they may be due to another disease.

In comparing our series with others, we stress that all our patients were investigated by radiography and that the follow-up period was long. Ceteris paribus this will make the recurrence rate high.

In our series there is a poor correlation between subjective symptoms and radiological findings. Radiological evidence of recurrence was found in a little more than one-third of the cases, which shows that the operation is hardly technically satisfactory. The persistence of symptoms in the patients who were followed up does not indicate that the method is ideal.

However, a comparison with previous operative methods is in favour of the Allison procedure, as e.g. Gertz, Regout, and Thomsen (1951) found about $50 \%$ radiological recurrences.

\section{SUMMARY}

A series of 70 patients operated upon for hiatal hernia is presented ; 55 were followed up an average of 7.6 years after the operation. Fifty-two patients were subjected to radiography which showed a satisfactory result in 31 , while 18 had a recurrence of the hernia ; in most of the latter the hernia was smaller than before operation. Thirty-one patients were symptom-free at followup. These were not the same patients, as the correlation between subjective and objective findings was poor.

It is concluded that the Allison operation for oesophageal hiatal hernia is not the ideal treatment; but more than half the patients were symptom-free an average of 7.6 years after the operation.

\section{REFERENCES}

Åkerlund, A. (1926). Hernia diaphragmatica hiatus oesophagei vom anatomischen und röntgenologischen Gesichtspunkt. Acta radiol. (Stockh.), 6, 3.

Allison, P. R. (1951). Reflux esophagitis, sliding hiatal hernia, and the anatomy of repair. Surg. Gynec. Obstet., 92, 419.

Barrett, N. R. (1952). Hiatus hernia. Proc. roy. Soc. Med., 45, 279.

Bloom, J. (1947). Hiatus herniae. Canad. med. Ass. J., 57, 9.

Brick, I. B. (1949). Clinical significance of hiatus hernia. Mississippi V. med. J., 71, 2.

and Amory, H. I. (1950). Incidence of hiatus hernia in patients without symptoms. Arch. Surg., 60, 1045.

Brintnall, E. S., Blome, R. A., and Tidrick, R. T. (1961). Late results of hiatus hernia repair. Amer. J. Surg., 101, 159.

Crawford, E. S., and DeBakey, M. E. (1958). Abdominal repair of hiatal hernia: A study of 138 cases. Ibid., $24,889$.

Engberg, H., Thomsen, G., and Vesterdal, J. (1957). Hiatus hernia in children. Acta paediat. (Uppsala), 46, 371 .

Gertz, T. C., Regout, J. E. P. M., and Thomsen, G. (1951). Late results in transthoracic herniotomies. Thorax, 6, 316.

Hill, L. D., Chapman, K. W., and Morgan, E. H. (1961). Objective evaluation of surgery for hiatus hernia and esophagitis. J. thorac. cardiovasc. Surg., 41, 60.

Husfeldt, E., Andreassen, M., Lindenberg, J., and Thomsen, G. (1960). Operative treatment of sliding hiatal hernia in adults. Acta chir. scand., Suppl. 253, p. 33.

Key, E. (1926). Hernia diaphragmatica hiatus oesophagi vom chirurgisch-therapeutischen Gesichtspunkt. Acta radiol. (Stockh.), 6, 35.

Morrison, L. B. (1925). Diaphragmatic hernia. J. Amer. med. Ass., 84,161 .

Pickard, C. (1952). The oesophago-gastric junction under a variety of conditions as examined by radiology. Thesis, Univ, of Leeds. (cit. Johnstone, A. S. (1952). The radiology of hiatus hernia. Proc. roy. Soc. Med., 45, 286.)

Sparks, J. V. (1958). Some post-operative findings in hiatus hernia. J. Fac. Radiol.(Lond.), $8,84$.

Sweet, R. H. (1953). Analysis of one hundred thirty cases of hiatus hernia treated surgically. J. Amer. med. Ass., 151, 376.

Thomsen, G. (1955). Hiatus Hernia in Children. A radiologic-clinica study comprising 58 cases. Danish Science Press, Copenhagen. Acta radiol. (Kbh.), Suppl. 129.

Turner, J. W. (1943). Gastric herniation of the esophageal hiatus. Amer. J. Roentgenol. $50,33$.

Werner, B., and Wiklund, T. (1959). Sliding esophageal hiatal hernia. Acta chir. scand., Suppl. 245, p. 173. 